\title{
Preparation of Microcapsules Containing Dye Aqueous Solution and Investigation of Release Feature According to Preparation Method
}

\author{
Yoshinari Taguchi, Natsukaze Saito, Masato Tanaka* \\ Graduate School of Science and Technology, Niigata University, Niigata-shi, Japan \\ Email: ${ }^{\star}$ tanaka@eng.niigata-u.ac.jp
}

How to cite this paper: Taguchi, Y., Saito, N. and Tanaka, M. (2017) Preparation of Microcapsules Containing Dye Aqueous Solution and Investigation of Release Feature According to Preparation Method. Journal of Encapsulation and Adsorption Sciences, 7, 83-94.

https://doi.org/10.4236/jeas.2017.72006

Received: May 26, 2017

Accepted: June 19, 2017

Published: June 23, 2017

Copyright $\odot 2017$ by authors and Scientific Research Publishing Inc. This work is licensed under the Creative Commons Attribution International License (CC BY 4.0).

http://creativecommons.org/licenses/by/4.0/

\begin{abstract}
Microcapsules containing the dye aqueous solution were prepared with three kinds of preparation methods and the release feature of microcapsules with each preparation method was mainly investigated. As a dye tried to microencapsulate, methylene blue was adopted, because methylene blue aqueous solution was changed in color with light irradiation and utilized in order to check the degree of river pollution. Microencapsulation using multiple emulsion was performed with the suspension polymerization method, the inverse interfacial polycondensation method and the suspension polymerization in parallel with the interfacial polymerization method, respectively. The release feature of microcapsules prepared with each preparation method was estimated with the solute permeability coefficient. It was found that the release feature of dye aqueous solution was different according to the preparation method and could be delicately controlled by microencapsulating with the suspension polymerization in parallel with interfacial polycondensation reaction and forming the polyurethane shell on the surface of the dye aqueous solution droplets.
\end{abstract}

\section{Keywords}

Microencapsulation, Methylene Blue, Permeability Coefficient, Multiple

Emulsion, Suspension Polymerization, Interfacial Polycondensation Reaction

\section{Introduction}

Various kinds of microcapsules have been prepared and applied to the various fields such as cosmetics, food materials, medicine, adhesives, information recording materials, textiles, and agricultural materials [1] [2] [3] [4], because the microcapsules can contain various substances and have many functions. Accordingly, microencapsulation technologies have gained increasing to interest these 
fields.

The main purposes of microencapsulation are to protect the active core materials from environment, to release the core material according to occasion demands, to modify the surface of core materials and to handle the gaseous and the liquid core materials as the fine solid particles.

Furthermore, novel functions of the microcapsules may be expected by selecting the combination of the shell materials and the core materials to microencapsulate, forming the hybrid shells and controlling the diameter and inner structure.

For example, as water is the good solvent to be able to dissolve many chemicals, the microcapsules containing various aqueous solution may be sure to give the many chances to apply them to new uses.

As the preparation methods of microcapsules containing aqueous solution, the following preparation methods have been reported, the suspension polymerization method [5] [6], the interfacial polycondensation method [7] [8], the gelling in liquid method [9], the melting dispersion cooling method [10] [11], and the inverse interfacial polymerization method [12]. These preparation methods cleverly used the multiple emulsion such as (W/O)/W emulsion [13] [14] [15] [16] [17].

As these preparation methods have merits and demerits, it is important to select the preparation method according to the purpose of microencapsulation, the expected functions and the necessary conditions for microcapsules such as diameter, the inner structure and the employed materials for the microcapsule shell.

Methylene blue of a basic dye has been widely used as oxidation - reduction indicator, vital staining and chemicals in photochemistry [18] [19].

Also, hitherto, as methylene blue has specific adsorption characteristic, methylene blue was used to check the pollution degree of rivers [20].

Accordingly, if methylene blue could be microencapsulated and released delicately, it may be expected that methylene blue may be actively put to practical use.

Taking these results into consideration, it was tried to investigate how the release feature of methylene blue aqueous solution is dependent on the preparation method of microcapsules.

The purposes of this study are to try to microencapsulate the methylene blue aqueous solution with a few preparation methods and to investigate the release feature of microcapsule according to each microencapsulation method.

\section{Experimental}

\subsection{Preparation of Microcapsules}

Materials used to prepare the microcapsules containing the dye aqueous solution were as follows.

Methylene Blue (MB: Wako Pure Chemical Ind., Ltd., Japan) was used as a dye of core material. Styrene monomer (St: Wako Pure Chemical Ind., Ltd., Japan) was used as a polymerazable monomer to form the microcapsule shell at 
the suspension polymerization process, where 2,2'-Azobis, (2,4-dimethylvaleronitrile) (V-65: Wako Pure Chemical Ind., Ltd., Japan) was dissolved as an initiator.

Methylene diphenyl 4,4'-diisocyanate (MDI: Tokyo Kasei Kogyo Ind., Ltd., Japan) and polyethylene glycol (PEG: Wako Pure Chemical Ind., Ltd., Japan) were used as an oil soluble monomer and a water soluble monomer at the interfacial polycondensation reaction process, respectively.

Polyglycerol polyricinolate (POEM: Riken Vitamin Ind., Ltd., Japan) and Soybean lechitin (SBL: Wako Pure Chemical Ind., Ltd., Japan) were used as oil soluble surfactants.

Sodium dodecylbenzenesulphonate (DBS: Wako Pure Chemical Ind., Ltd., Japan) and Tricalcium phosphate (TCP: Wako Pure Chemical Ind., Ltd., Japan) were used as a water soluble surfactant and a particulate stabilizer, respectively.

Corn oil (Wako Pure Chemical Ind., Ltd., Japan) was used as the continuous phase at the inverse interfacial polycondensation method.

The experimental apparatus used to prepare the microcapsules is the same as the previous one [21].

Figure 1 shows the flow sheets for preparing the microcapsules containing the dye aqueous solution with the suspension polymerization method (Figure 1(a)), with the inverse interfacial polycondensation reaction method (Figure 1(b)) and with the suspension polymerization method in parallel with the interfacial polymerization method (Figure 1(c)).

First, the preparation of microcapsules with the suspension polymerization method was as follows.

The dye aqueous solution of the given volume was added into styrene monomer (St) and stirred with homogenizer to form the (W/O) emulsion. In styrene monomer, V-65 and POEM or SBL were dissolved beforehand as an initiator and an oil-soluble surfactant, respectively.

Then, prebulk polymerization was performed in the (W/O) emulsion under the conditions such as $\mathrm{T}=70^{\circ} \mathrm{C}, \mathrm{t}=30 \mathrm{~min}$ and $\mathrm{Nr}=200 \mathrm{rpm}$ in order to increase the viscosity of styrene monomer and to stabilize the (W/O) emulsion. After this operation, the $(\mathrm{W} / \mathrm{O})$ emulsion was added in the continuous water phase and stirred with the six-bladed impeller to form the (W/O)/W emulsion. Then, suspension polymerization was conducted under the conditions such as $\mathrm{Nr}=300 \mathrm{rpm}$ and $\mathrm{T}=70^{\circ} \mathrm{C}$ for $8 \mathrm{~h}$. The model microcapsule prepared thus was shown in Figure 1(a). Hereafter, the suspension polymerization method and the microcapsules prepared were called Process A and MCS, respectively.

Second, the preparation of microcapsules with the inverse interfacial polycondensation reaction method was as follows. The dye aqueous solution dissolving PEG was added into the corn oil of the continuous phase and stirred to form the $(\mathrm{W} / \mathrm{O})$ emulsion under the conditions such as $\mathrm{Nr}=300 \mathrm{rpm}$ and $\mathrm{T}=$ $70^{\circ} \mathrm{C}$ for $10 \mathrm{~min}$. Then, the corn oil of $10 \mathrm{cc}$ dissolving MDI was added to the (W/O) emulsion and the interfacial polycondensation reaction was conducted under the conditions such as $\mathrm{Nr}=300 \mathrm{rpm}$ and $\mathrm{T}=70^{\circ} \mathrm{C}$ for $24 \mathrm{~h}$. The model 


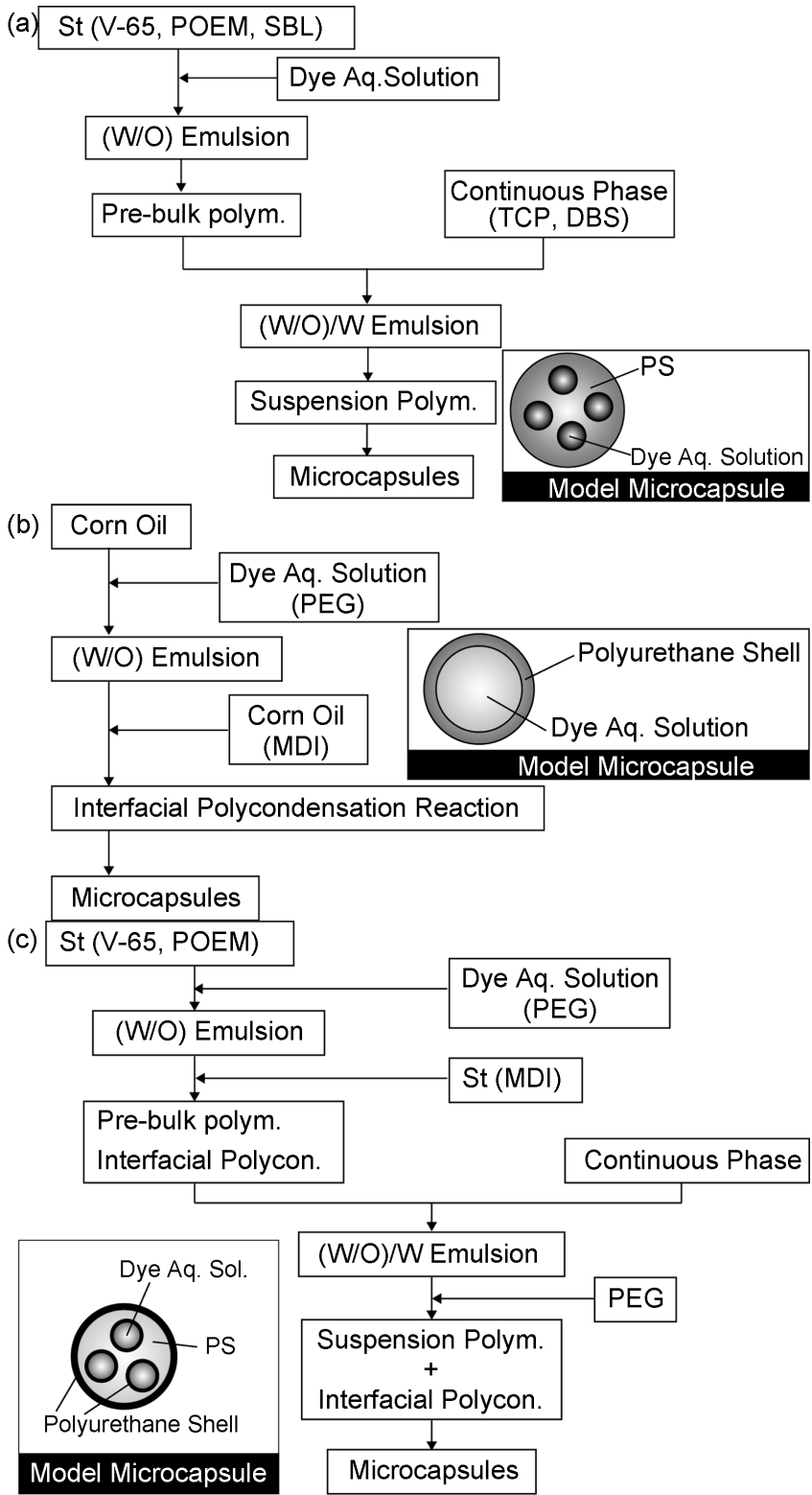

Figure 1. Flow sheets for preparing microcapsules.

microcapsule prepared thus was shown in Figure 1(b). Hereafter, the inverse interfacial polycondensation reaction method and the microcapsules prepared were called Process B and MCI, respectively.

Third, the preparation of microcapsules with suspension polymerization in parallel with interfacial polycondensation reaction was as follows.

The dye aqueous solution dissolving PEG was added in styrene monomer and stirred to form the (W/O) emulsion. Then, St dissolving MDI of a given amount was added into the $(\mathrm{W} / \mathrm{O})$ emulsion and the interfacial polycondensation reaction was started in parallel with bulk polymerization under the conditions such as $\mathrm{Nr}=200 \mathrm{rpm}, \mathrm{t}=30 \mathrm{~min}$ and $\mathrm{T}=70^{\circ} \mathrm{C}$ to form the polyurethane shell on the interface between the inner water droplet and styrene monomer.

After bulk polymerization was conducted for $30 \mathrm{~min}$, the (W/O) emulsion was 
added into the continuous water phase, stirred to form the (W/O)/W emulsion and then, suspension polymerization was conducted for $7 \mathrm{~h}$ under the conditions such as $\mathrm{Nr}=300 \mathrm{rpm}$ and $\mathrm{T}=70^{\circ} \mathrm{C}$. In this microencapsulation method, the polyurethane shell may be formed on the surface of microcapsule by adding PEG into the continuous water phase.

The model microcapsule prepared thus was shown in Figure 1(c).

Hereafter, the suspension polymerization method in parallel with interfacial polycondensation reaction and the microcapsules prepared were called Process C and MCSI (1), respectively.

The experimental conditions are shown in detail in Table 1.

Table 1. Experimental conditions.

\begin{tabular}{|c|c|c|c|}
\hline \multicolumn{2}{|c|}{ Process A } & Process B & Process C \\
\hline \multicolumn{2}{|c|}{ Dye Aqu. Solution } & Dye Aqu. Solution & Dye Aqu. Solution \\
\hline Dye & $0.1 \mathrm{~g}$ & Dye $\quad 0.1 \mathrm{~g}$ & Dye $\quad 0.1 \mathrm{~g}$ \\
\hline \multirow[t]{2}{*}{ Water } & $26.8 c c$ & $26.8 \mathrm{cc}$ & Water $\quad 26.8 \mathrm{cc}$ \\
\hline & & PEG $\quad 0 \sim 3.1 \mathrm{~g}$ & $0 \sim 3.1 \mathrm{~g}$ \\
\hline \multicolumn{4}{|c|}{ Monomer Mixture } \\
\hline St & $0.0 \mathrm{~g}$ & Continuous Phase & Monomer Mixture \\
\hline V-65 & $1.0 \mathrm{~g}$ & Corn Oil $200 \mathrm{cc}$ & St $\quad 20.0 \mathrm{~g}$ \\
\hline POEM & I $\quad 1.0 \mathrm{~g}$ & MDI $\quad 5.0 \mathrm{~g}$ & $\mathrm{~V}-65 \quad 1.0 \mathrm{~g}$ \\
\hline \multirow[t]{2}{*}{ SBL } & $1.0 \mathrm{~g}$ & & POEM $1.0 \mathrm{~g}$ \\
\hline & & Formation of $(\mathrm{W} / \mathrm{O})$ & SBL $\quad 1.0 \mathrm{~g}$ \\
\hline \multicolumn{2}{|c|}{ Continuous Phase } & $\mathrm{Nr} \quad 300 \mathrm{rpm}$ & MDI $\quad 0 \sim 2.0 \mathrm{~g}$ \\
\hline Water & $340 \mathrm{cc}$ & $\mathrm{t} \quad 10 \mathrm{~min}$ & \\
\hline TCP & $6.0 \mathrm{~g}$ & $\mathrm{~T} \quad 70^{\circ} \mathrm{C}$ & \multirow{2}{*}{$\begin{array}{l}\text { Continuous Phase and } \\
\text { Formation of }(\mathrm{W} / \mathrm{O})\end{array}$} \\
\hline \multirow{2}{*}{\multicolumn{2}{|c|}{ DBS $\quad 0.2 \mathrm{~g}$}} & & \\
\hline & & Polymerization & the same ad Process A \\
\hline \multicolumn{2}{|c|}{ Formation of $(\mathrm{W} / \mathrm{O})$} & $\mathrm{Nr} \quad 300 \mathrm{rpm}$ & \\
\hline $\mathrm{Nr} \quad 12$ & $2,000 \mathrm{rpm}$ & $\mathrm{t} \quad 24 \mathrm{~h}$ & Prepolymerization \\
\hline $\mathrm{t} \quad 1$ & $10 \mathrm{~min}$ & $\mathrm{~T} \quad 7^{\circ} \mathrm{C}$ & Interfacial Polym. \\
\hline & $20^{\circ} \mathrm{C}$ & & $\mathrm{Nr} \quad 200 \mathrm{rpm}$ \\
\hline & & & $\mathrm{t} \quad 30 \mathrm{~min}$ \\
\hline \multicolumn{2}{|c|}{ Prepolymerization } & & $\mathrm{T} \quad 70^{\circ} \mathrm{C}$ \\
\hline $\mathrm{Nr}$ & $200 \mathrm{rpm}$ & & Prebulk Polym. \\
\hline $\mathrm{t} \quad 3$ & $30 \mathrm{~min}$ & & the same ad Process A \\
\hline \multicolumn{4}{|c|}{$\mathrm{T} \quad 70^{\circ} \mathrm{C}$} \\
\hline \multirow{2}{*}{\multicolumn{2}{|c|}{$\begin{array}{c}\text { Formation of }(\mathrm{W} / \mathrm{O}) / \mathrm{W} \text { and } \\
\text { Polymerization }\end{array}$}} & & $\begin{array}{c}\text { Formation of }(\mathrm{W} / \mathrm{O}) / \mathrm{W} \text { and } \\
\text { Polymerization }\end{array}$ \\
\hline & & & the same ad Process A \\
\hline $\mathrm{Nr}$ & $300 \mathrm{rpm}$ & & \\
\hline $\mathrm{t}$ & $8 \mathrm{~h}$ & & \\
\hline $\mathrm{T}$ & $70^{\circ} \mathrm{C}$ & & \\
\hline
\end{tabular}




\subsection{Characterization}

\subsubsection{Observation}

The whole and inner structure of microcapsules prepared were observed by optical microscope (BH-2: OLYNPUS Co., Ltd., Japan) and scanning electron microscope (SEM: JST-5800, JEOL Ltd., Japan). From these photographs, the difference in the inner structure and the surface of microcapsule due to the preparation method was discussed.

\subsubsection{Mean Diameter of Microcapsules}

The mean diameters of microcapsules were calculated from the photographs taken by optical microscope. Here, the mean diameters are the Sauter mean diameters.

\subsubsection{Microencapsulation Efficiency}

The microencapsulation efficiency $(\lambda)$ was measured as follows.

After the microencapsulation process was finished, the concentration of dye in the continuous water phase was measured by the spectrophotometer (UV-160A: Shimazu Seisakusho Ltd., Kyoto, Japan).

If the concentration of dye was detected, the dye might be released during the microencapsulation process.

Comparing the measured values with the correlation curve, the dye concentration released during the microencapsulation process was estimated and then, the microencapsulation efficiency was calculated according to Equation (1).

$$
\lambda[\%]=\text { Microencapsulated dye weight/Initial dye weight } \times 100
$$

\subsubsection{Transient Release Feature}

Transient release feature of dye for the microcapsules prepared with each method was measured as follows.

Namely, the microcapsules of given weight $(1 \mathrm{~g})$ were added in the continuous water phase $(30 \mathrm{cc})$ and then, the concentration of dye released from the microcapsules was measured by the spectrophotometer at the constant time intervals.

From the values of the concentration measured, the transient release feature was estimated and permeability coefficient $(P)$ was calculated according to Equation (2).

$$
P=-\left(V_{s} / A C_{o}\right) \times C / t
$$

where $V_{s}, A, C_{o}, C, t$, are the volume of continuous water phase, the surface area of microcapsules, the initial concentration of dye in the microcapsule, the concentration of dye in the continuous water phase at any time, the elapsed time, respectively.

\section{Results and Discussion}

\subsection{Observation of Microcapsules}

Figure 2 shows the SEM photographs of microcapsules prepared with each method. 
The microcapsules (MCS) prepared with Process A (Figure 2(a) and Figure 2(b)) are found to be the spherical particles with the diameter of ca. $450 \mu \mathrm{m}$ and to be the multi core type. Furthermore, the microcapsule prepared with POEM seems to contain more water (Figure 2(b)) compared with the microcapsule prepared without POEM (Figure 2(a)).

The microcapsule (MCI) prepared with the Process B (Figure 2(c)) is found to be the mono core type.

While, the microcapsules (MCSI) prepared with Process C (Figure 2(d) and Figure 2(e)) are found to be the multi core type. Also, it is found that the diameters of inner water droplets were different due to the oil soluble surfactant species.

Anyway, the microcapsules containing the dye aqueous solution could be prepared with the preparation methods adopted here.

\subsection{Microencapsulation Efficiency for Each Microcapsule}

Figure 3 shows the microencapsulation efficiency $(\lambda)$ of microcapsules prepared by each preparation method, where the mean diameters $(\mathrm{Dp})$ of microcapsules are shown, too.

The microencapsulation efficiency of microcapsules prepared with each preparation method was $8.8 \%$ for MCS, $100 \%$ for MCI, $96 \%$ for MCSI, respectively.

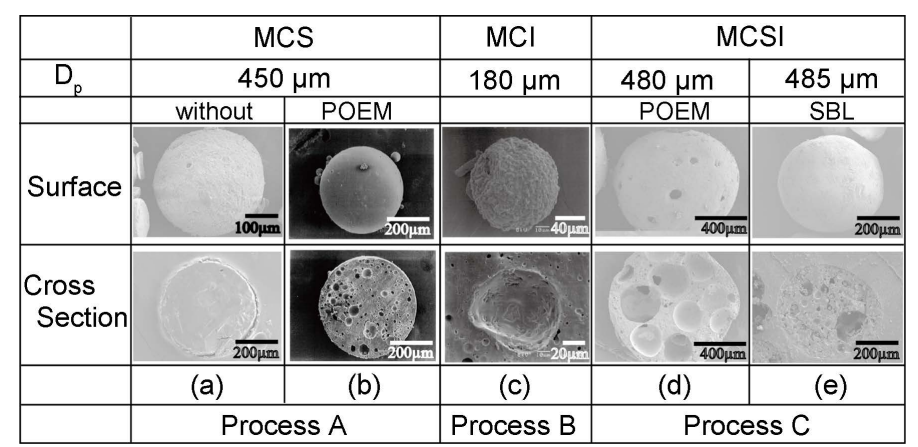

Figure 2. SEM photographs of microcapsules prepared with each preparation method.

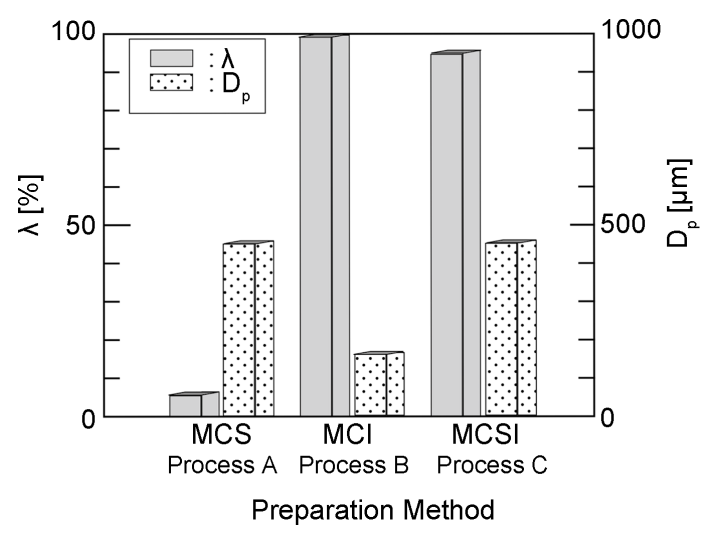

Figure 3. Microencapsulation efficiency and mean diameter of microcapsules prepared with each preparation method. 
While, the mean diameter of each microcapsule was $480 \mu \mathrm{m}$ for MCS, $180 \mu \mathrm{m}$ for MCI, $480 \mu \mathrm{m}$ for MCSI, respectively.

In the case of Process $\mathrm{A}$, as the microcapsules were prepared by using the (W/O)/W emulsion, the dye aqueous solution may be easily released on breaking the $(\mathrm{W} / \mathrm{O})$ emulsion into the continuous water phase and on forming the (W/O) droplets [22]. As a result, the microencapsulation efficiency may become low $(\lambda=$ ca. $8.8 \%)$.

In the case of Process B, as the microcapsules were prepared by using the (W/O) emulsion and by performing the inverse interfacial polycondensation reaction, the dye aqueous solution was never released into the oil phase at the microencapsulation process. As a result, the microencapsulation efficiency must become $100 \%$ just after preparation.

In the case of Process $\mathrm{C}$, as the inner dye aqueous droplets could be stabilized with the polyurethane resin shell and the double shells were formed, the microencapsulation efficiency may become high $(\lambda=$ ca. $96 \%)$.

\subsection{Release Feature}

It was investigated how the release feature for each microcapsule was depending on the preparation method.

Figure 4 shows the optical microscopic photographs of microcapsules used to estimate the release feature.

As MCI could not be dried as solid powder, the photograph for $\mathrm{MCI}$ was the microcapsule slurry. The microcapsules became blue in color due to the dye (methylene blue) aqueous solution. A few tiny holes are observed on the surface of microcapsules (MCS, MCSI).

Figure 5 shows the transient release features for the microcapsules prepared with each preparation method. In the case of MCI prepared with Process B, the dye aqueous solution was rapidly released. This may be due to the porous shell as shown in Figure 6.

It is well known that the porous shell is formed for the microcapsules prepared with the interfacial polycondensation reaction method which is suitable to microencapsulate the liquid core material [7] [12]. Accordingly, the tiny holes may be easily formed on the polyurethane shell. In the case of MCS prepared with Process A, the dye aqueous solution was released relatively slow because of the denser shell. While, in the case of MCSI prepared with Process C, the dye

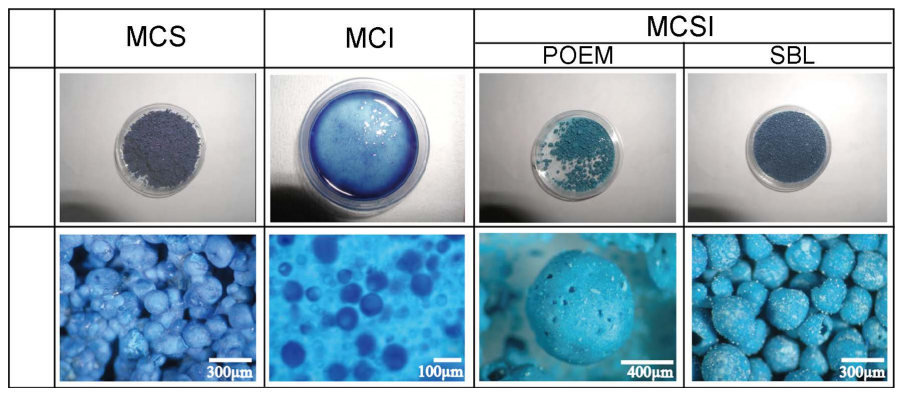

Figure 4. Optical microscopic photographss of microcapsules. 


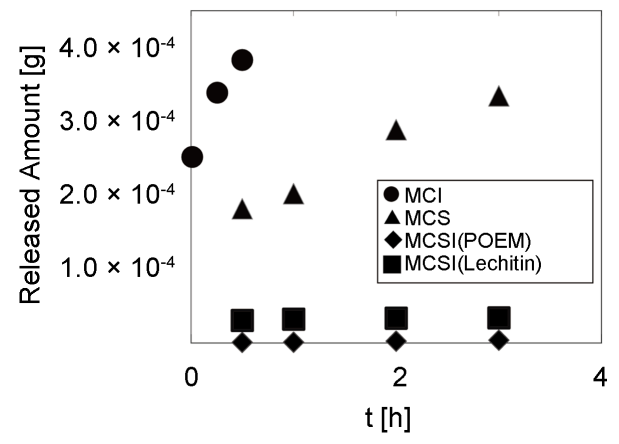

Figure 5. Transient release features for each microcapsule.
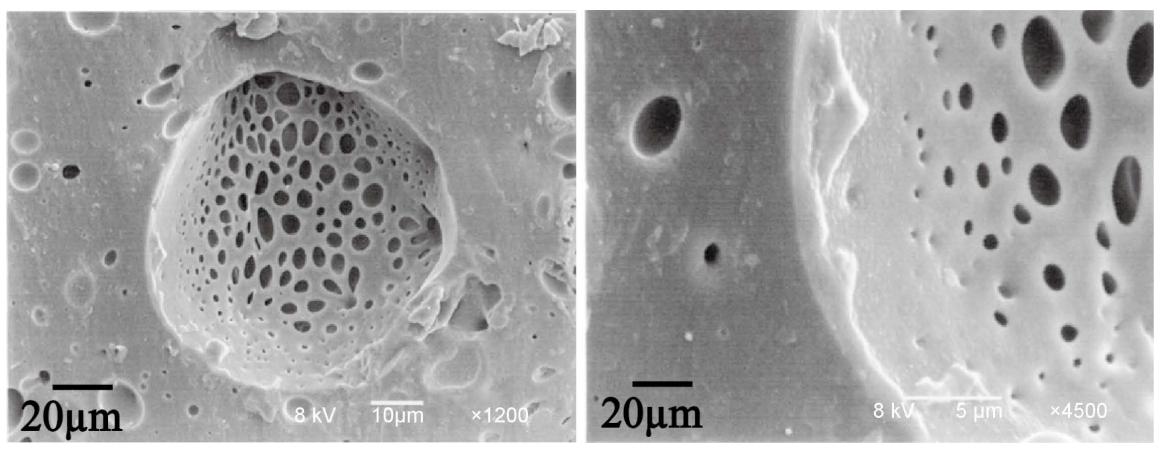

Figure 6. SEM photographs of microcapsule shell of MCI.

aqueous solution was released remarkably slow. Especially, when POEM was used as an oil soluble surfactant added to stabilize the (W/O) emulsion, the release of the dye aqueous solution was prevented to a certain degree.

From these results, MCSI prepared with Process C was the most suitable to the loading and releasing capability and the microencapsulation efficiency.

\subsection{Estimation of Permeability Coefficient}

From the results obtained above, it was found that the release velocity of the dye aqueous solution from the microcapsules was considerably different depending on the preparation method.

So, the release feature for MCSI was investigated in detail changing the conditions of the interfacial polycondensation reaction, namely, the concentrations of MDI and PEG.

Figure 7 shows the transient feature for MCSI prepared changing the concentrations of MDI and PEG.

The release velocity was decreased with the concentrations of MDI and PEG, where the microcapsules without MDI and PEG were MCS. The values of permeability coefficient were estimated from Equation (2) by obtaining the initial values of $(C / t)$ as shown in Figure 7. Here, it was investigated how permeability of dye aqueous solution was affected by the formation of polyurethane shell.

The values of permeability coefficient for each microcapsule are shown in $\mathrm{Ta}$ ble 2 together with the concentration of PEG [Cp: $\left./ \mathrm{cm}^{2}\right]$ per unit interfacial area of the $(\mathrm{W} / \mathrm{O})$ emulsion. 


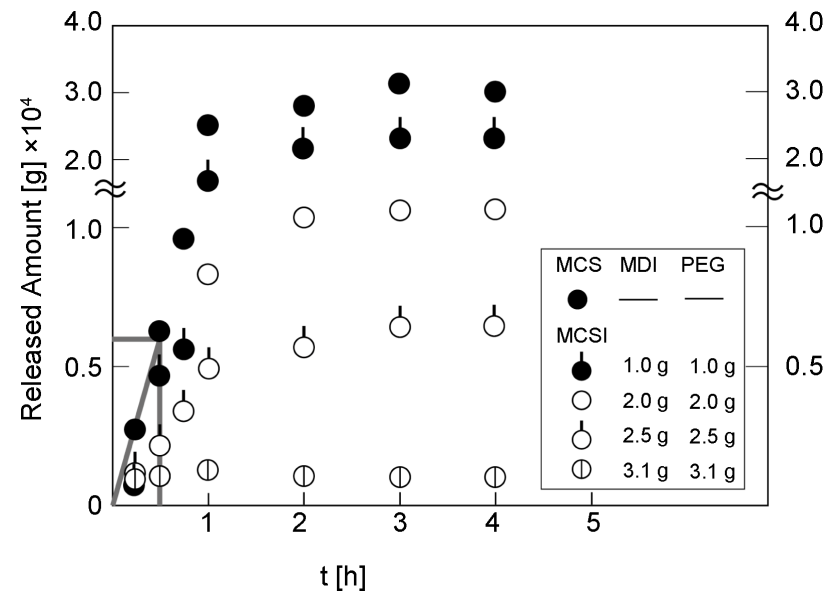

Figure 7. Transient features for MCSI.

Table 2. Values of permeability coefficients.

\begin{tabular}{cccccc}
\hline$\left[\mathrm{g} / \mathrm{cm}^{2}\right]$ & 0 & $6.5 \times 10^{-4}$ & $1.3 \times 10^{-3}$ & $1.6 \times 10^{-3}$ & $2.0 \times 10^{-3}$ \\
\hline$[\mathrm{cm} / \mathrm{s}]-P \times 10^{5}$ & 7.7 & 5.2 & 4.6 & 3.6 & 1.3 \\
\hline
\end{tabular}

It was found that the release velocity could be delicately controlled by changing the concentration (Cp) of PEG.

Furthermore, if PEG is added in the continuous water phase at the suspension polymerization process, the release of the dye aqueous solution could be more minutely controlled.

\section{Conclusions}

The microcapsules containing the dye aqueous solution were prepared with the suspension polymerization method, the inverse interfacial polycondensation reaction method and the suspension polymerization in parallel with inverse interfacial polycondensation reaction.

The release feature of dye aqueous solution for each microcapsule was measured and estimated with the permeability coefficient.

The following results were obtained.

1) The dye aqueous solution could be microencapsulated with each preparation method.

2) The microencapsulation efficiency with the inverse interfacial polycondensation reaction method became $100 \%$ just after preparation, however, the dye aqueous solution was rapidly released.

3) The release feature for microcapsules with each preparation method was estimated with the permeability coefficient.

4) The release of the dye aqueous solution for the microcapsules prepared with suspension polymerization in paralled with interfacial polycondensation reaction could be delicately controlled by changing the concentration of polyethylene glycol in the inner aqueous phase.

Moreover, if methylene diphenyl 4,4-dissoyanate is added into the continuous 
water phase, the polyurethane shell is formed on the surface of the microcapsules and the more minute controlled release may become possible.

\section{References}

[1] Kondo, T. and Koishi, M. (1975) Microcapsules (Preparation, Properties, Application). Sankyo Shuppan, Tokyo.

[2] Kondo, T. (1967) Saishin Maikurokapseruka Gijutsu (Microencapsulation Technique). TES, Tokyo.

[3] Tanaka, M. (2008) Key Point of Preparation of Nano/Microcapsules. Techno System Publishing Co. Ltd., Tokyo.

[4] Koishi, M., Eto, K. and Kogure, H. (2005) (Preparation + Utilization) Microcapsules. Kogyo Chosakai, Tokyo.

[5] Mizuno, K., Taguchi, Y. and Tanaka, M. (2010) Preparation of Microcapsules Containing Water Phase as a Core Material by Using UV-Curable Resin-Effect of Surfactants on Stability of W/O Emulsion. Membrane, 35, 146-152.

https://doi.org/10.5360/membrane.35.146

[6] Nakamura, D., Yokoyama, H., Taguchi, Y. and Tanaka, M. (2014) Preparation of Microcapsules Containing Water Droplets Stabilized with Solid Powder and Application to Blowing Agent. Materials Sciences and Applications, 5, 20-26. https://doi.org/10.4236/msa.2014.51003

[7] Morita, R., Saito, N., Taguchi, Y. and Tanaka, M. (2015) Preparation of Microcapsules Containing Phase Change Material and Silicon Carbide Powder with Interfacial Polycondensation Reaction Method. Materials Sciences and Applications, 6, 251-262. https://doi.org/10.4236/msa.2015.63030

[8] Taguchi, Y., Aoki, M. and Tanaka, M. (2014) Preparation of Microcapsules Containing Triple Core Materials with Interfacial Condensation Reaction. Journal of Cosmetics, Dermatological Sciences and Applications, 4, 275-283. https://doi.org/10.4236/jcdsa.2014.44037

[9] Oppermann, A.K.L., Renssen, M., Schuch, A., Stieger, M. and Scholten, E. (2015) Effect of Gelation of Inner Dispersed Phase on Stability of $\left(\mathrm{W}_{1} / \mathrm{O} / \mathrm{W}_{2}\right)$. Food Hydrocolloids, 48, 17-26. https://doi.org/10.1016/j.foodhyd.2015.01.027

[10] Koyama, Y., Saito, N., Fuchigami, K., Taguchi, Y. and Tanaka, M. (2015) Microencapsulation of Sodium Hydrogen Carbonate to Generate Carbon Dioxide with Thermal Responsible Shell Material. Journal of Cosmetics, Dermatological Sciences and Applications, 5, 36-44. https://doi.org/10.4236/jcdsa.2015.51005

[11] Taguchi, Y., Yamamoto, R., Saito, N. and Tanaka, M. (2014) Preparation of Microcapsules Containing Aqueous Solution of Azur B with Melting Dispersion Cooling Method and Application to DNA Amplification Detector. Journal of Encapsulation and Adsorption Sciences, 4, 15-24. https://doi.org/10.4236/jeas.2014.41003

[12] Hayashi, Y., Fuchigami, K., Taguchi, Y. and Tanaka, M. (2014) Preparation of Microcapsules Containing Erythritol with Interfacial Polycondensation Reaction by Using the (W/O) Emulsion. Journal of Encapsulation and Adsorption Sciences, 4, 132-141. https://doi.org/10.4236/jeas.2014.44014

[13] Kong, Y.-Q., Li, D. and Adhikari, B. (2011) Preparation of Gelatin Microparticles Using Water-in-Water (w/w) Emulsification Technique. Journal of Food Engineering, 103, 9-13. https://doi.org/10.1016/j.jfoodeng.2010.09.012

[14] Hernández-Marín, N.Y., Lobato-Calleros, C. and Vernon-Carter, E.J. (2013) Stability and Rheology of Water-in-Oil-in-Water Multiple Emulsions Made with Protein-Polysaccharide Soluble Complexes. Journal of Food Engineering, 119, 181-187. 
https://doi.org/10.1016/j.jfoodeng.2013.05.039

[15] Cofrades, S., Santos-Lopez, J.A., Freire, M., Benedí, J., Sanchez-Muniz, F.J. and Jimenez-Colmenero, F. (2014) Oxidative Stability of Meat Systems Made with $\mathrm{W}_{1} / \mathrm{O} / \mathrm{W}_{2}$ Emulsions Prepared with Hydroxytyrosol and Chia Oil as Lipid Phase. LWT-Food Science and Technology, 59, 941-947. https://doi.org/10.1016/j.lwt.2014.06.051

[16] Kaimainen, M., Marze, S., Järvenpää, E., Anton, M. and Huopalaht, R. (2015) Encapsulation of Betalain into W/O/W Double Emulsion and Release during in Vitro Intestinal Lipid Digestion. LWT-Food Science and Technology, 60, 899-904. https://doi.org/10.1016/j.lwt.2014.10.016

[17] Schuch, A., Wrenger, J. and Schuchmann, H.P. (2014) Production of W/O/W Double Emulsions. Part II: Influence of Emulsification Device on Release of Water by Coalescence. Colloids and Surfaces A: Physicochemical and Engineering Aspects, 462, 344-351. https://doi.org/10.1016/j.colsurfa.2013.11.044

[18] Kwoles, A. and Gurnani, S. (1972) A Study of the Methylene Blue-Sensitized Oxidation of Amino Acid. Photochemistry and Photobiology, 16, 95-108. https://doi.org/10.1111/j.1751-1097.1972.tb07341.x

[19] Sheng, C.K. and Yunus, W.M.M. (2005) Study of Photobleaching Mechanism in Methylene Blue Sensitized Gelatin Using a Single Beam UV-Vis. Fibre Optics Spectrophotometer. Pertanike Journal of Science \& Technology, 13, 23-30.

[20] Li, Y., Du, Q., Liu, T., Peng, X., Wang, J., Sun, K., Wang, Y., Wu, S., Wang, Z., Xia, Y. and Xia, L. (2013) Comparative Study of Methylene Blue Dye Adsorption onto Activated Carbon, Graphene Oxide, and Carbon Nanotubes. Chemical Engineering Research and Design, 91, 361-368. https://doi.org/10.1016/j.cherd.2012.07.007

[21] Taguchi, Y., Ito, D., Saito, N., Kimura, I. and Tanaka, M. (2017) Preparation and Characterization of Microcapsules Containing Particulate Phosphorescent Agent with Suspension Polymerization. Polymers for Advanced Technologies, 28, 379385. https://doi.org/10.1002/pat.3899

[22] Taguchi, Y., Saito, N., Uchida, A. and Tanaka, M. (2016) Preparation of Thermosensitive Microcapsules Containing Water Soluble Powder by Melting Dispersion Cooling Method. Journal of Encapsulation and Adsorption Sciences, 6, 57-69. https://doi.org/10.4236/jeas.2016.63006

Scientific Research Publishing

Submit or recommend next manuscript to SCIRP and we will provide best service for you:

Accepting pre-submission inquiries through Email, Facebook, LinkedIn, Twitter, etc. A wide selection of journals (inclusive of 9 subjects, more than 200 journals)

Providing 24-hour high-quality service

User-friendly online submission system

Fair and swift peer-review system

Efficient typesetting and proofreading procedure

Display of the result of downloads and visits, as well as the number of cited articles

Maximum dissemination of your research work

Submit your manuscript at: http://papersubmission.scirp.org/

Or contact jeas@scirp.org 